\author{
INTERNATIONAL UNION OF PURE \\ AND APPLIED CHEMISTRY \\ APPLIED CHEMISTRY DIVISION \\ COMMISSION ON FOOD ADDITIVES
}

\title{
SURVEY OF ANALYTICAL METHODS AVAILABLE FOR THE ESTIMATION OF ARTIFICIAL SWEETENERS IN FOOD
}

\section{Prepared for publication by}

B. D. PAGE and H. B. S. CONACHER

Food Research Division, Health and Welfare Canada, Ottawa, Canada 


\section{PREFACE}

Dr. H. Egan, President, Applied Chemistry Division, had suggested that the Commission on Food Additives (at the time a part of the former Food Section, Dr. R. Marcuse (Sweden) Chairman) consider the need for updating the "Survey of analytical methods available for the estimation of some food additives in food" (Food Section, Applied Chemistry Division, IUPAC: Pure Appl. Chem. 26 (1) 77 (1971).)。Shortly before, the FAO-WHO Expert Committee on Food Additives had published the report "Specifications for the identity and purity of food additives and their toxicological evaluation: some flavoring substances and non-nutritional sweetening agents" (FAO Nutrition Meetings Report Series No. 44; WHO Technical Report Series No. 383 (1968)). In its 1974 program the Commission had included a limited survey of methods available for artificial sweeteners to determine if additional work in that field was desirable. This report was prepared by Dr. E. Somers (Canada), then a Titular Member of the Commission. While his report did not reveal need for additional work, it presented an excellent basis for updating the earlier survey, which included only sorbitol as a sweetening agent. Because of a change in assignment and in the area of his responsibilities, Dr. Somers could not undertake the necessary expansion and revision of his initial report. However, he kindly arranged for two colleagues in his former department to do so. Accordingly, the Commission is indebted to Drs. B. D. Page and H. B. S. Conacher, Food Research Division, Foods Directorate, Health Protection Branch, Health and Welfare Canada, Ottawa, Ontario, for this comprehensive report submitted in 1975 . At its meeting in Madrid 1975 the Commission recommended publication of the report as a supplement to the cited survey Publication has been somewhat delayed because it was anticipated that another survey updating methods for individual antioxidants could be published as a joint supplement. However, the latter survey has not yet been cleared for publication and at its Paris 1976 meeting the Commission recommended that publication of the artificial sweetener survey proceed. 
SURVEY OF ANALYTICAL METHODS AVAILABLE FOR THE ESTIMATION OF ARTIFICIAL SWEETENERS IN FOOD

B. D. Page and H. B. S. Conacher

Food Research Division, Foods Directorate, Health Protection Branch, Health and Welfare Canada, Ottawa, Ontario KIA OL2

\title{
INTRODUCTION
}

In this report, methods available for the determination of several artificial sweeteners in foods are reviewed. The sweeteners reviewed include:

\author{
Cyclamates (cyclohexylsulfamates) \\ Saccharin (1,2-benzisothiazol-3-one 1,1-dioxide) \\ Polhydric Alcohols \\ Aspartame (INN) \\ Glycyrrhizin \\ Dihydrochalcones
}

\section{CYCLAMATES}

Chemical name: Cyclohexylsulfamic acid.

Physical properties: Cyclamic acid is a white solid, m.pt.184 ${ }^{\circ}$. Calcium cyclamate is a white odorless crystalline powder, readily soluble in water, propylene glycol, and aqueous ethanol. Sodium cyclamate is a white odorless crystalline powder, readily soluble in water, soluble in propylene glycol, and practically insoluble in ethanol.

Analytical methods

Cyclamic acid may be determined directly as cyclamic acid or its methyl ester. It may be hydrolysed and determined as cyclohexylamine or sulfate. Also, cyclamic acid may be analysed as cyclohexyl nitrite, cyclohexene, cyclohexanol, or sulfate by reaction with nitrous acid.

\section{(1) Clean-up methods}

(i) Extraction - Most extractive clean-up methods are based on the strongly acidic nature of cyclamic acid. Thus, it may be extracted from strongly acidified soft drinks or aqueous food extracts by ethyl acetate (Refs. 1,2,3,4,5\&6), isobutyl methyl ketone (4-methylpentan-2-one) (Refs. 7 \& 8), or ether (Ref. 9). Preliminary extractive clean-up of the acidic solution may be done with hexane (Ref.6), petroleum ether (Refs. 4 \& 10), or chloroform followed by petroleum ether (Ref. 11). Alternatively, either basic or weakly acidic aqueous solutions of beverages or food extracts containing cyclamic acid may be purified by extraction with ether (Ref. 1), light petroleum (Refs. 4 \& 12), chloroform followed by light petroleum (Ref. 13), ether-petroleum ether (Ref. 14), hexane (Ref. 6), ethyl acetate (Ref. 15), isobutyl methyl ketone (Ref. 8), or cyclohexane (Ref. 3). Cyclamic acid may also be extracted by nitrobenzene with the tris(1,10-phenanthroline) iron (II) ion (ferroin) (Ref. 16). Sodium cyclamate, formed by adding sodium hydroxide to a soft drink, may be extracted from the residue after evaporation with boiling ethanol (Refs. 17 \& 18 ).

(ii) Ion exchange - Weakly basic ion exchange resins such as Amberlite CG-4B (Ref. 19), and strongly basic resins such as Amberlite CG-400 (Ref. 20) have been used to isolate cyclamic acid from aqueous solutions. Elution of cyclamic acid from the resins can be performed with dilute hydrochloric acid (Ref. 19), or methanolic oxalic acid (Ref. 20). Dowex 50W, a strongly acidic cation exchange resin, has been used to remove interfering amines prior to hydrolysis in a colorimetric method for cyclamic acid based on cyclohexylanine determination (Ref. 21), and to remove interfering cations before reduction of cyclamic acid in a colorimetric method based on sulfate determination (Ref. 22). Duolite C-3 (cation exchange resin) has been used to regenerate cyclamic acid from isolated sodium cyclamate (Refs. $17 \& 18$ ).

(iii) Dialysis - Dialysis has been used to isolate cyclamic acid from aqueous extracts or suspensions of food (Refs. $2,5 \& 23$ ).

(iv) Precipitation - Aqueous solutions of acidified soft drinks or food extracts have been clarified by filtration after treatment with Carrez type reagents (Refs.10, 
$11,13,24$ \& 25). Interfering barium-insoluble material must be removed prior to reduction of the cyclamic acid in its gravimetric determination as barium sulfate (Refs.26, $27 \& 28$ ).

(v) Column chromatography - A silica gel column has been used to clean up extracts of cyclamic acid from various food commodities (Ref. 6).

\section{(2) Chromatographic methods}

(i) Paper chromatography - Many solvent systems are reported to resolve cyclamic acid from other artificial sweeteners and/or preservatives (Refs. 5,20,29,30,31 \& 32 ).

(ii) Thin-layer chromatography - Silica (Refs. 2,4,9,33,34,35\& 36), polyamide (Refs. 6,36 \& 37), alumina (Ref. 36), DEAE-cellulose (2-diethylaminoethyl cellulose) and cellulose (Ref. 36), cellulose-polyamide (Ref. 38), acetylated cellulose-polyamide (Refs.14, $39 \& 40$ ), and a reversed phase system (Ref. 41) have all been used in conjunction with various solvent systems to separate and identify cyclamic acid. One system, shown by collaborative study to be suitable for soft drinks is Absorbosil-1, developed by butan-1-ol, $95 \%$ ethanol, ammonium hydroxide, and water $(40+4+1+9)$ (Refs. 40 \& 35).

(iii) Detection of spots - Cyclamic acid yields visible spots with indicator dyes (Refs. 6 \& 36), silver nitrate reagents (Refs. 31,32,34 \& 36), phthalic anhydride-aniline (Ref. 29), chloranil (tetrachlorocyclohexadiene-1,4-dione) (Ref. 35), acidic p-dimethylaminobenzaldehyde (Ref. 6) and,after spraying with acidic hydrogen peroxide, quinhydrone (Ref.30) and o-toluidine (Ref. 2). Pinacryptol yellow (6-ethoxy-1-methyl-2-(m-nitrostyryl)quinolinium chloride) (Refs. 6 \& 36), bromine (spray or vapour) followed by fīuorescein (Refs. 4, 9 \& 41) and then by N-2-aminoethyl-1-naphthylamine (Ref. 36), and dichlorofluorescein (Refs. 14, 33 \& 42) allow cȳclamic acid to be seen under ultraviolet light. After oxidation with nitrous acid, cyclamic acid is detected as the sulfate (Ref. 5).

\section{(¿v) Gas chromatogiaphy}

(a) Methyl cyclamate - Cyclamic acid may be determined in soft drinks after methylation with diazomethane as methyl cyclamate (Ref. 1).

(b) Cyclohexene - Cyclohexene, produced by reaction of nitrous acid on cyclamic acid, may be used to determine cyclamic acid in soft drinks (Refs. 10,11 \& 13) after extraction into a nonpolar solvent. Automated head space analysis of the produced cyclohexene has been used to identify and quantitate cyclamates in food (Ref. 43).

(c) Cyclohexyl nitrite - Cyclohexyl nitrite, produced under strong nitrosating conditions, allows determination of cyclamic acid in soft drinks (Ref. 10).

\section{(3) Spectroscopic methods}

(i) Infrared - Cyclohexene, formed by the reaction of nitrous acid on cyclamic acid, can be used to determine cyclamate in foods. The cyclohexene produced is extracted into light petroleum and determined at $1650 \mathrm{~cm}^{-1}$ (Refs. $44 \& 45$ ).

(ii) Ultraviolet - Cyclamic acid may be determined by the addition of excess chlorine to an acidic, aqueous solution of cyclamate to give $\mathrm{N}, \mathrm{N}$-dichlorocyclohexylamine. The ultraviolet absorption of the dichloro compound at $314 \mathrm{~nm}$ is used to quantitate cyclamate in a wide variety of liquid foods (Ref. 3 ).

\section{(4) Colorimetric methods}

(i) Determination of cyclohexylamine - Cyclamate present in canned fruit has been determined as cyclohexylamine after pressurized acid hydrolysis. The cyclohexylamine is extracted by chloroform from the hydrolyzate at $\mathrm{pH} 12$, coupled with p-benzoquinone, and measured spectrophotometrically at $493 \mathrm{~nm}$ (Refs. $46 \& 47$ ). Alternatively, acidic hydrogen peroxide (Refs. 21,48,49\&50) or acidic dimethyl sulfoxide (Ref. 51) may be used to produce cyclohexylamine. In these instances, the cyclohexylamine may be coupled with quinhydrone before (Refs. 21 \& 48) or after (Refs. 21, 48 \& 51) extraction with chloroform to determine cyclamate in a wide variety of foods. Similarly, cyclohexane may be coupled with picryl chloride to determine cyclamate in soft drinks (Ref. 50). Pyridine, with $10 \%$ water, was found to degrade cyclamate. The resulting cyclohexylamine was determined after treatment with base and extracting the resulting colour into cyclohexane at $340 \mathrm{~nm}(\operatorname{Ref}$. 52).

(ii) Determination as cyclohexyl nitrite - Nitrosation of cyclamic acid to cyclohexyl nitrite, then extraction, diazotization, coupling with N-2-aminoethyl-1-naphthylamine, and measurement at $550 \mathrm{~nm}$ quantitates cyclamate in soft drīnks (Ref. 53).

(iii) Determination as cyclohexanol - Cyclohexyl nitrite, prepared as above, may be converted to cyclohexanol with sulfamic acid. The cyclohexanol forms a greenish product with vanillin-sulfuric acid which is determined at $655 \mathrm{~nm}$ (Ref. 23).

(iv) Determination as sulfate- Sulfate from action of nitrous acid on cyclamate yields the highly coloured acid chloranilate ion from barium chloranilate at pH 4 . The 
coloured ion is measured spectrophotometrically at $530 \mathrm{~nm}$ and permits determination of cyclamate in soft drinks (Ref. 22).

(v) Determination as unreacted nitrous acid - Excess nitrous acid is added to soft drinks and the unconsumed nitrous acid is determined at $610 \mathrm{~nm}$ after reaction with safranine (3,7-diamino-2,8-dimethyl-5-phenylphenazonium chloride) (Ref。25)。.

(vi) Other methods - The ferrion-cyclamate reaction in chloroform is used to estimate cyclamate in foods (Refs. $7 \& 8$ ). The fluorescence formed by treating cyclamic acid with bromine vapour and fluorescein during thin-layer chromatographic visualization is measured at $540 \mathrm{~nm}$ after extraction of the silica gel with ethanol (Ref. 9). Cyclamic acid, can be extracted with ferroin reagent and, thereafter, can be colorimetrically determined in nitrobenzene (Ref. 16). The bluish 1:1 complex of cyclamic acid and methylene blue in neutral solution can be extracted into chloroform and measured at $660 \mathrm{~nm}$ to determine cyclamic acid (Ref. 54).

(5) Titrimetric methods

The degradation of cyclamate to sulfate by nitrous acid and the determination of the sulfate by titration has been useful to estimate cyclamate. Thus, sulfate can be determined by the E.D.T.A. method, in which excess barium salt is determined after precipitation of barium sulfate (Refs. 15 \& 55). Sulfate may also be titrated directly with a soluble barium salt, with hydroquinone to indicate excess barium (Ref. 56). Cyclamate may be determined by direct titration with sodium nitrite in acidified soft drink, using an electrometric endpoint determination (Ref. 57).

(6) Gravimetric methods

Cyclamic acid has been isolated from soft drinks and weighed directly (Ref. 17). All other gravimetric procedures involve quantitation of cyclamate as barium sulfate formed during degradation of cyclamic acid with nitrous acid in the presence of barium chloride. This permits determination of cyclamate in nonalcoholic beverages (Refs. 17, 24 \& 27), wines (Refs. $26 \& 58$ ), and other food extracts (Ref. 28).

(7) Identification

Cyclamic acid may be identified after isolation and purification by its optical crystallographic properties (Ref. 18). Spot tests, based on a barium sulfate precipitate or turbidity, have been described (Refs. 12 \& 59). Extracted cyclamic acid, dissolved in propylene glycol-ethanol, develops a purple colour after addition of hydrogen peroxide and chloranil (Ref. 60).

(i) Polarographic method - Cyclamic acid is decomposed with nitrous acid. The excess lead, after precipitation of the sulfate with lead acetate, is determined by polarography (Ref. 61).

(ii) Turbidimetric method - Barium sulfate turbidity, formed by the addition of barium chloride to nitrous acid cyclamate solutions, may be used to quantitate cyclamate (Refs. $19 \& 52$ ).

\section{REFERENCES}

1. H. B. S. Conacher and R. C. O'Brien, J. Assoc. Offic. Analyt. Chem. 54, 1135 (1971).

2. T. Hayashi, H. Watanabe, K. Takamura, and A. Tanimura, Shokukior Eiseigaku Zassi. 13, 74 (1972); cited in Chem. Abstr. 77, 99719r (1972).

3. D. Hoo and C. Hu, Anal. Chem. 44, 2111 (1972).

4. T. Korbelak, J. Assoc. Offic. Analyt. Chem. 52, 487 (1969).

5. S. Matsunoto, Tokyo Toritsu Eisei Kenkyusho Nempo. 21, 89 (1969); cited in Chem. Abstr. $76,125492 \mathrm{n}(1972)$.

6. R. Takeshita, J. Chromatogr. 66, 283 (1972).

7. S. DiPasquale, A. DeRobertis and L. Ciraolo, Ann. Fac. Econ. Commer., Univ. Studi Messina. 6, 15 (1968); cited in Chem. Abstr. 72, 537902 (1970).

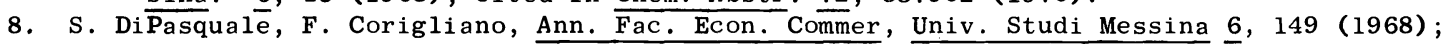
cited in Chem. Abstr. $72,53791 b(1970)$.

9. D. K. Das, T. V. Mathew and S. N. Nitra, J. Chromatogr. 52, 354 (1970).

10. J. A. Dalziel, R. M. Johnson and A. J. Shenton, Analyst $\overline{97}, 719$ (1972).

11. D. I. Rees, Analyst 90, 568 (1965).

12. W. S. Cox, J.Assoc. Offic. Analyt. Chem. 35, 321 (1952).

13. M. L. Richardson and P. E. Laton, Analyst $\overline{91}, 520$ (1966).

14. H.Woidich, H. Gnauer and E. Galinovsky, Z. Lebensm. - Untersuch. 139, 142 (1969).

15. Y. Mihoshi and F. Kobayashi, Tokyo Yakka Dargaku Kenkyu Nempo 13, $\frac{130}{80}$ (1963); cited in Chem. Abstr. 62, 8942f (1965).

16. Y. Hayashi, J. Sci. Hiroshima Univ., Ser. A-2 35, 147(1971).

17. J. B. Wilson, J. Assoc. Offic. Analyt. Chem. 35,465 (1952).

18. A. H. Tillson and J. B. Wilson, J. Assoc. Offic. Analyt. Chem. 35, 467 (1952). 
19. K. Asano, M. Taira, H. Nakanishi and E. Senda, Nichidai Igaku Zasshi 22, 797 (1963); cited in Chem. Abstr. 61, 8813h (1964).

20. T. Komoda and R. Takeshita. Shokuhin Eiseigaku Zasshi 3 , 382 (1962); cited in Chem. Abstr. 60, 6130f (1964).

21. S. Kojima and H. Ichibagase, Yakugaku Zasshi 83, 1114 (1963).

22. A. J. Harrison and A. Cook, J. Assoc. Pub. Anal. 7, 42 (1969).

23. M. Takeuchi, H. Kashiwagi, K. Washizuka and T. Matsūi, Eisei Kagaku 18, 324 (1972); cited in Chem. Abstr. 78, 7032lq (1973).

24. P. Czuczy and I. Pinter, Elelmiszervizsgalati Kozlemenyck 19, 97 (1973); cited in Food Sci. Tech. Abstr. 6, 5T250 (1974).

25. A. J. Shenton and R. M. Johnson, Analyst 98, 749 (1973).

26. M. T. Giordano and V. Pennati, Div. Viticolt. Enol. 18, 357 (1965); cited in Chem. Abstr. 64, $4224 \mathrm{f}(1966)$.

27. J. B. Wilson, J. Assoc. Offic. Analyt. Chem. 38, 559 (1955).

28. Nordisk Metodikk - Kommitte for Livsmedel, UDC 547.592.1 Nr. 42, 1962 .

29. D. K. Das and T. V. Mathew, J. Instn. Chem., India, 41, 192 (1969); cited in Analyt. Abstr. 19, 5181 (1970).

30. H. Ichibagase and S. Kojima, J. Pharm. Soc. Japan 82, 1016 (1962); cited in Analyt. Abstr. 10, 5391 (1963).

31. I. S. Ko, I. S. Chung and Y. H. Park, Depts. Natl. Chem. Lab. (Korea) 3 , 72 (1959); cited in Chem. Abstr. 54, 10181c (1960).

32. L. C. Mitchell, J. Offic. Analyt. Chem. 38, 943 (1955).

33. M. C. De la Torre Boronat and M. Camprubi Ribalta, Circ. Form. 30, 231 (1972); cited in Chem. Abstr. 77, 163090h (1967).

34. W. Kamp, Pharm. Weekbl. Ned. 101, 57 (1966); cited in Anal. Abstr. 14, 3555 (1967).

35. T. Korbelak and J. N. Bartlett, J. Chromatgr. 41, 124 (1969).

36. K. Nagasawa, H. Yoshidome and K. Anryu, J. Chromatogr. 52, 173 (1970).

37. R. T. Wang and S. S. Chau, J. Chin. Chem. Soc. (Taipei) 17, 188 (1970); cited in Chem. Abstr. 74, 41174f (1971).

38. Y. Mihashi and F. Kobayashi, Tokyo Yakka Diagaku Kenkyu Nempo 22, 159 (1972); cited in Chem. Abstr. 80, 46584y (1974).

39. T. Salo and K. Salminen, Suomenkemistilehti 37, Pt. A. 161 (1964); cited in Chem. Abstr. 62, 3382e (1965).

40. T. Salo, E. Aird and K. Salminen, Z. Lebensm. - Untersuch. 125, 20 (1964).

41. R. T. Wany, S. S. Chou and C. H. Lin, Hua Hsueh No. 1-2, 27 (1969); cited in Chem. Abstr. 72, 99198s (1970).

42. B. Mueller, and J. Ludwig, Mitterlungsbl. GDCh (Ges. Deut. Chem.) - Fackgruppe Lebensmittelchem. Gericht1. Chem. 26, 3 (1972); cited in Chem. Abstr. 78, 41667b (1973).

43. Von W. Grockel and A. Wessels, Deutsche. Lebensm.-Rundschau 68, 393 (1972).

44. D. Coppini and A. Albasini, Mitt. Geb. Lebensmittelunters. U. Hyg. 59, 239 (1968); cited in Anal. Abstr. 17, 3051 (1969).

45. D. Coppini and A. Albasini, Mitt. Geb. Lebensmittelunters. U. Hyg. 60, 456 (1969); cited in Anal. Abstr. 20, 2105 (1971).

46. D. E. Johnson, H. B. Nunn and S. Bruckenstein, Analyt. Chem. 40, 368 (1968).

47. D. E. Johnson and H. B. Nunn, J. Offic. Analyt. Chem. 51, $127 \overline{4}$ (1968).

48. S. Kojima and H. Ichibagase, Yakugaku Zasshi 83, 1108 (1963).

49. M. Ichikawa, S. Kojima and H. Ichibagase, Yakugaku Zasshi 84, 563 (1964).

50. B. A. Saturley, J. Assoc. Offic. Analyt. Chem. 55, 892 (1972).

51. K. Kazuyoshi, Japan Analyst 20, 606 (1971); Analyt. Abstr. 23, 2800 (1972).

52. K. Nagasawa, H. Yoshidome and J. Kishi, Eisei Kagaku 14, 203 (1968); cited in Chem. Abstr. 70, 27686k (1969).

53. A. J. Shenton and R. M. Johnson, Analyst 98, 745 (1973).

54. T. Shibata, H. Isaka and K. Yoshimura, Japan Analyst 20, 850 (1971); cited in Analyt. Abstr. 23, 2801 (1972).

55. A. M. C. Davies, J. Assoc. Public Analysts 4 , 11 (1966).

56. A. Vercillo and A. Manzone, Rend. Ist. Super Sonita 24, 644 (1961); cited in Chem. Abstr. 56, 14679h (1962).

57. M. L. Richardson and P. E. Luton, Analyst 91, 522 (1966).

58. E. Kielhoger and H. Aumann, Wein-wiss. Beiheft Fachzeit. deut. Weinbau 9 , 1 (1955); cited in Chem. Abstr. 50, 5975e (1956).

59. F. Feigl, D. Goldstein and Libergot $t$ Z. Lebensm.-Untersuch. 139, 230 (1969).

60. S. Gianferrara, Rass. Chim. 11, 17 (1959); cited in Chem. Abstr. 55 , 829a (1961).

61. Y. Kurayuki, Y. Mizunoya and H. Kojima, Yakugaku Zasshi 86, 890 (1966). 


\section{SACCHARIN}

Chemical name: 1,2-Benzisothiazol-3-one 1,1-dioxide (trivially, 2-sulfobenzoic imide, 0benzosulfamide).

Physical properties: Saccharin occurs as white crystals or as a white crystalline powder m. pt. 226-230 . It is odourless or has a faint aromatic odour. It is soluble in alcohol and slightly soluble in water, chloroform and ether. Sodium saccharin occurs as white crystals or as a wite crystalline powder. It is odourless or has a faint aromatic odour. It readily dissolves in water and is soluble in alcohol.

\section{Analytical methods}

\section{(1) Clean-up methods}

(i) Extraction - Saccharin may be readily extracted from acidified solutions of liquid foods or aqueous food extracts with solvents such as chloroform, ether, ethyl acetate, benzene, or isobutyl methyl ketone either singly or as a mixture. Thus, saccharin may be extracted from non-alcoholic beverages or soft drinks (Refs. $1,2,3,4,5,6,7$ \& 8), from alcoholic beverages (Refs. 5, 9, 10 \& 11), fruit juices (Refs. 3, 5 \& 11), pickling brine (Ref. 12), liquid foods (Ref. 13) and aqueous food extracts (Refs. 10,13, 14 \& 15). In some instances, preliminary extractive clean-up may be carried out on a basic solution with ether (Ref. 2) or chloroform-benzene (Ref. 3) prior to acidification and saccharin extraction. The acidified aqueous food extract or beverage may also be extracted with petroleum ether (Ref. 4) or hexane (Ref. 13) in order to remove lipid-soluble interfering substances. Saccharin may also be extracted by nitrobenzene with ferroin reagent(Ref. 16).

(ii) Ion exchange - Weakly basic ion exchange resins such as Amberlite LA-2 (Refs. $17 \& 18$ ) and Amberlite CG-4B (Ref. 19) and strongly basic resins such as Amberlite CG-400 (Ref. 20) have been used to isolate saccharin from aqueous solutions. Saccharin can be eluted from the resins with dilute hydrochloric acid (Ref. 19) or methanolic oxalic acid (Ref. 20).

(iii) Dialysis - Dialysis has been used to isolate saccharin from aqueous food extracts (Ref. 14).

(iv) Precipitation - Acidified fruit juices and aqueous food suspensions may be clarified by the addition of lead acetate followed by filtration prior to gravimetric (Ref. 11) or colorimetric (Ref. 3) determination of saccharin. The Carrez type reagent may also be used to clarify aqueous food extracts prior to silylation and gas chromatographic analysis (Ref. 17).

(v) Column chromatography - An ethyl acetate extract of saccharin can be further purified by absorption and elution from a silica gel column (Ref. 13).

(2) Chromatographic methods

(i) Paper chromatography - Many solvent systems have been developed which permit detection of saccharin in the presence of other artificial sweeteners and/or preservatives (Refs. 14,15,20,21,22,23,24\&25).

(ii) Thin layer chromatography - Silica gel (Refs. 4,26,27,28 \& 29), polyamide (Refs. 13, $26 \&$ 30), alumina (Ref. 26), DEAE-cellulose (2-diethylaminoethyl cellulose) (Ref. 26), cellulose (Ref. 26), cellulose-polyamide (Ref. 31), acetylated cellulose-polyamide (Refs. $32 \& 33$ ) and a reversed phase system (Ref. 34) have all been used in conjunction with numerous solvent systems to separate and identify saccharin. The thin layer system of Absorbosil-1 (or Silica gel H) with n-butanol, 95\% ethanol, ammonium hydroxide, and water $(40+4+1+9)$ as developing solvent, has been shown by collaborative study to be suitable for the determination of saccharin in soft drinks (Ref. 4).

(iii) Detection of spots - Saccharin may be detected by its blue fluorescence under $254 \mathrm{~nm}$ ultraviolet light (Refs. 4,13,14,26 \& 29). Saccharin is also detectable under ultraviolet light after reaction with: indicator dyes (Refs. 13 \& 26), silver nitrate-pyrogallol reagents (Refs. 15, 24 \& 26), phthalic acid-aniline (Ref. 21) $\alpha$-naphthylamine-cupric acetate (Ref. 22), pinacryptol yellow (6-ethoxy-l-methyl-2-(m-nitrostyryl)quinolinium chloride)(Ref. 13), and chloranil followed by $\alpha$-naphthylamine (Rēf. 27). Bromine (spray or vapour) followed by $2^{\prime}, 7^{\prime}$ dichlorofluorescein (Refs. $34 \& 36$ ) or fluorescein and N-2-aminoethyl-1-naphthylamine (Ref. 26) allow detection of saccharin by ultraviolet or visible light, respectively. Resorcinol may be used to detect the trichloromethylthio derivative of saccharin (Ref, 35).

(iv) Gas chromatography -

(a) As methyl derivative - Saccharin may be readily methylated by diazomethane and determined by gas chromatography on 3\% JXR (Ref. 2) or 20\% SE30 (Ref. 37). This method has been applied to soft drinks (Ref. 2).

(b) As silyl derivative - Saccharin N-trimethylsilyl ether is readily pre- 
pared and analyzed by gas chromatography on a mixed phase of $3 \%$ ov-1 and $1.5 \%$ ov-22 (Ref.17). The saccharin content of wine, sauerkraut and marmalade has been determined.

(c) As trichloromethylthio derivative - The trichloromethylthio derivative of saccharin may be determined by gas chromatography on $1.5 \%$ ov-1 (Ref. 35).

(d) A.s benzenethiol - Sacuharin may be reduced to benzenethiol and determined by gas chromatography (Ref. 38).

(v) High speed liquid chromatography - This method has been applied to the determination of saccharin in a variety of soft drinks and other artificially sweetened liquid foods by direct injection without prior clean-up (Refs. 39 \& 40).

(3) Spectrophotometric methods

(i) Infrared - Following extraction, the purified saccharin is mixed with potassium bromide and the absorption measured at $1721 \mathrm{~cm}^{-1}$ to quantitate saccharin (Ref. 41).

(ii) Ultraviolet - Saccharin can be determined by measuring its ultraviolet absorption at $278 \mathrm{~nm}$ after extraction into chloroform and oxidation of interferences with permanganate (Ref. 9), or after ion exchange clean-up (Ref. 19).

\section{(4) Colorimetric methods}

(i) Nessler reagent - Saccharin is hydrolyzed by aqueous hydrochloric acid and the resulting ammonium chloride is determined using the Nessler reagent (Refs. 1 \& 8 ).

(ii) Phenol-sulfuric acid method - Saccharin is converted to phenolsulfonphthalein (3,3-bis(4-hydroxyphenyl )-2,1-benzoxathiole 1,1-dioxide) by heating with phenol and sulfuric acid. The addition of sodium hydroxide gives a red colour with a maximum absorbance at 558 $\mathrm{nm}$, which is specific for saccharin (Ref. 3).

(iii) p-Dimethylaminobenzaldehyde method - The colour developed by reaction of p-dimethylaminobenzaldehyde and saccharin is measured at $450 \mathrm{~nm}$ and allows quantitation of saccharin (Ref. 7).

(iv) Other methods - The ferroin-saccharin reaction in chloroform is used to estimate saccharin in foods (Ref. 6). After removal of interferences by permanganate oxidation, saccharin can be determined at $522 \mathrm{~nm}$ after addition of 1,10-phenanthroline and Mohr's salt (ammonium ferrous sulfate)(Ref. 5). Saccharin, extracted with ferroin, may be determined colorimetrically in nitrobenzene (Ref. 16).

\section{(5) Gravimetric}

(i) Sublimation of saccharin - Preliminary extraction of acidic aqueous sample with carbon tetrachloride is followed by ether extraction and evaporation. Sublimation at reduced pressure purifies saccharin which is transferred from the sublimation apparatus and weighed (Ref. 42).

(ii) As barium sulfate - An aqueous acid solution is extracted with ether. The residue after evaporation of the ether is fused with sodium and potassium carbonate. The melt is extracted with water and the sulfate precipitated as barium sulfate (Refs. $10,11 \&$ 12).

\section{(6) Identification}

(i) Organoleptic - The residue after evaporation of the ether extract of acidified liquid food or aqueous extract is tested for sweet taste (Ref. 43).

(ii) As salicylic acid - The ether extract of acidified aqueous food extract or beverage is evaporated and redissolved in water. Oxidation in sulfuric acid with permanganate gives salicylic acid, which affords a violet colour on addition of ferric chloride (Ref. 44).

(iii) Phenol-sulfuric acid test - The residue on evaporation of the ether extract (see (i) and (ii) above) gives a magenta colour after heating with phenol-sulfuric acid followed by addition of sodium hydroxide (Ref. 45).

(iv) Reduction to hydrogen sulfide - Saccharin may be detected after reduction with Raney nickel in dilute sodium hydroxide. The addition of hydrochloric acid liberates hydrogen sulfide which is detected using lead acetate paper (Ref. 46).

\section{REFERENCES}


page 382 , Section 20.183, W. Horwitz, Editor, Washington, D.C. (1975)

2. H. B. S. Conacher and R. C. O'Brien, J. Assoc. Offic. Analyt. Chem. 53,1117 (1970).

3. E. Fernandez-Flores, A. R. Johnson, B. Leker, D. Larry and S. Lerner, J. Assoc. Offic. Analyt. Chem. 56, 1411 (1973).

4. T. Korbelak, J. Assoc. Offic. Analyt. Chem. 52, 487 (1969).

5. F. Corigliano, Atti. Congi. Qual. 6th, 361 (1967); cited in Chem. Abstr. 73, 119263k(1970)

6. S. DiPasquale and F. Corigliano, Ann. Fac. Econ. Commer., Univ. Studi Messina 6 , 149 (1968); cited in Chem. Abstr. 72, 53791b (1970).

7. Y. Mihasha and F. Lobayoshi, Tokyo Yakku Daigaka Kenkyu Nempo 13, 80 (1963); cited in Chem. Abstr. 62, $8942 f$ (1965).

8. S. Krauze, W. Miskiewicz and I. Bak, Roczn. panst. Zabl. Hig. 16, 33 (1965); cited in Anal. Abstr. 13, 3207 (1966).

9. G. Bosile, Boll. Lab. Chim. Prov. 17, 544 (1966); cited in Chem. Abstr. 66, 36579x (1967).

10. J. R. Markus, J. Assoc. Offic. Anal. Chem. 56, 162 (1973).

11. Official Methods of Analysis of the Association of Official Analytical Chemists, 12th ed., page 381, Section 12.180, W. Horwitz, Editor, Washington, D. C. (1975).

12. F. Kodmon, Konzerv-Paprikaipar 1, 23 (1967); cited in Chem. Abstr. 67, 99034g (1967).

13. R. Takeshita, J. Chromatogr. 66, 283 (1972).

14. S. Matsumoto, Tokyo Troitsu Eisei Kenkyusho Kenkyu Nempo 21, 89 (1969); cited in Chem. Abstr. 76, 125492n (1972).

15. W. Miskiewicz, Roczn. panst. Zakl. Hig. 16, 33 (1965); Chiem. Abstr. 7\%, 131\%sh (1972).

16. Y. Hayashi, J. Sci. Hiroshima Univ. Ser. A-2 35, 147 (1971); cited in Chem. Abstr. 77, 18173h (1972).

17. R. Gerstl and K. Ranfft, Z. Anal. Chem. 258, 110 (1972).

18. H. Woidich, H. Gnauer and E. Galinovsky, Z. Lebensm.-Untersuch. 139 , 143 (1969).

19. K. Asono, M. Taira, H. Nakanishi, E. Senda, Y.Shiraishi and R. Takeshita, Nichidai Igaku Zasshi 22, 797 (1963); cited in Chem. Abstr. 61, 8813h (1964).

20. T. Komoda and R. Takeshita, Shokuhin. Eisegaku Zasshi 3 , 382 (1962); cited in Chem. Abstr. 60, 6130f (1964).

21. D. K. Das and T. V. Mathew, J. Instn. Chem., India 41, 192 (1969); cited in Anal. Abstr. 19,5181 (1970).

22. H. Ichibagase and S. Kojima, Yakugaku Zasshi 82, 1616 (1962); cited in Chem. Abstr. 58, 8357g (1963).

23. I. S. Ko, I. S. Chung and Y. Park, Repts. Natl. Chem. Lab. (Korea) 3 , 72 (1959); cited in Chem. Abstr. 54, 10181c (1960).

24. L. C. Mitchell, J. Assoc. Offic. Analyt. Chem. 38,943 (1955).

25. W. Miskiewicz, Rocn. Panst. Zakl. Hig. $16,33(1965)$; cited in Chem. Abstr. $62,16875 e$ (1965).

26. K. Nagasawa, H. Yoshidome and K. Anryu, J. Chromatogr. 52, 173 (1970).

27. T. Korbelak and J. N. Bartlett, J. Chromatogr. 41, 124 (1969).

28. W. Kamp, Pharm. Weekbl. Ned. 101, 57 (1966); cited in Analyt. Abstr. 14, 3555 (1967).

29. M. C. De Ia Torre Boronat and M. Camprubi Ribalta, Circ. Farm. 30, 23I (1972); cited in Chem. Abstr. 77, 163090h (1972).

30. R. T. Wang and S. S. Chou, J. Chin. Chem. Soc. (Taipei) 17, 188 (1970); cited in Chem. Abstr. 74, $41174 \mathrm{f}$ (197i).

31. Y. Mi hashi and F. Kobayashi, Tokyo Yakka Daigaku Kenkyu Nempo 22, 159 (1972); cited in Chem. Abstr. 80, 46584y (1974).

32. T. Salo, E. Airo and K. Salminen, Z. Lebens.-Untersuch. 124, 20 (1964).

33. T. Salo and K. Salminen, Suomen Kemistilehti 37, Pt. $\underline{\text { A }}, \overline{161}$ (1964); cited in Chem. Abstr. 62, 3382e (1965).

34. R. T. Wang, S. S. Chou and C. H. Lin, Hua Hsueh 1-2, 27 (1969); cited in Chem. Abstr. 72 , 99198s (1970).

35. M. Maktia, S. Yamamoto and K. Yoshihara, Eisei Kagaku 19, 297 (1973); cited in Chem. Abstr. 81, 2457a (1974).

36. B. Mullier and J. Ludwig, Mittelungsbl. G.D. Ch (Oes. Deut. Chem.) - Fachgruppe Lebensmittel chem. Oericht1. Chem. 26, 3 (1972); cited in Chem. Abstr. 78, 41667b (1973).

37. W. Groebel, Z. Lebens.-Untersuch. 129, 153 (1966).

38. H. Kuroda and H. Hirose, Shokuhin Eiseigaku Zasshi 12, 322 (1971); cited in Chem. Abstr. 76, $44756 \mathrm{z}$ (1972).

39. J. J. Nelson, J. Chromatogr. Sci. 11, 28 (1973).

40. B. Brinitz, J. Assoc. Offic. Analyt. Chem. 55, 278 (1972).

41. D. Coppini and A. Albasini, Mitt. Geb. Lebensmittelunters u. Hyg. $\underline{59}, 239$ (1968); cited in Analyt. Abstr. 17, 3051 (1969).

42. Official Methods of Analysis of the Association of Official Analytical Chemists, i2th ed., page 382, Section 20.182 , W. Horwitz, Editor, Washington, D. C. (1975).

43. Ibid., page 381 , Section 20.177 .

44. Ibid., page 381, Section 20.178.

45. Ibid., page 381, Section 20.179.

46. F. Feigl, D. Goldstein and E. Libeigott, Z. Lebensm:-Untersuch. 139, 230 (1969). 


\section{POLYHYDRIC ALCOHOLS}

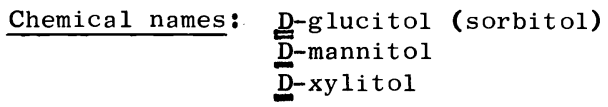

Physical properties: Sorbitol is a white hygroscopic powder; when anhydrous, m.pt. 110$112^{0}$; freely soluble in water, partly soluble in hot alcohol, and slightly soluble in cold alcohol, methanol or acetic acid. Mannitol occurs as white crystals or crystalline pouder, m.pt. 166-168 . Xylitol occurs as white crystals, m.pt.93-94.5\% The solubilities of mannitol and xylitol are similar to those of sorbitol.

\section{Analytical methods}

(1) Clean-up methods

(i) Extraction - Polyhydric alcohols may be extracted from solid or semi-solid foods with alcohol (Refs. 1 \& 2), aqueous alcohol (Refs. 3, 4 \& 5) or water (Refs. 6 \& 7) Hexane may be used for preliminary defatting (Refs. 1, 2 \& 4). Liquid foods are usually clarified by filtration.

(ii) Ion-exchange - Wines have been de-ionized by passing through anion and cation exchange columns after treatment with activated carbon (Ref. 8). Interfering organic acids may also be removed by ion-exchange (Ref. 9).

(iii) Precipitation - Interfering organic acids have been removed by precipitation as their lead salts (Ref.3).

\section{(2) Chromatographic methods}

(i) Paper chromatography - Paper chromatography with propanol-ethyl acetate-water (7:1:2) has been used to separate and identify sorbitol (Ref. 8). Ammonium molybdate treatment of Whatman No. 1 paper and development with butanol-pyridine water (6:4:3) may be used to separate several sugars and polyhydric alcohols (Ref. 10).

(ii) Thin-layer chromatography - Silica gel (Ref. 11), boric acid treated silica gel (Ref. 12) or calcium sulfate (Ref. 13) may be used in the separation of polyhydric alcohols and sugars with water (Ref. 12), chloroform-methanol (2:1)(Ref. 13) or ethanol-isobutyl alcohol-water (Ref. 11) as developing solvents.

(iii) Detection of spots - Sorbitol and mannitol may be detected using acidic periodate followed by benzidine (Ref. 8). Basic silver nitrate has been used to locate sugars and polyhydric alcohols (Ref. 10). Alkaline permanganate (Refs. 11 \& 12) and sulfuric acid (Ref. 13) detect sugars and sugar alcohols.

\section{(iv) Gas chromatography}

(a) As acetates - Sorbitol may be determined in bakery products, wines and vinegars as the acetate derivative on $10 \%$ DC-200 (Ref. 2). Acetates of sorbitol, mannitol and xylitol have also been utilized in their determination in dietetic biscuits (Ref. 4) using a mixed phase of QF-l(trifluoropropylmethyl siloxane) and BDS (butanediol succinate polyester). The chromatographic properties of sorbitol (Refs. 14 \& 15) and mannitol (Refs. 14 \& 15) hexaacetates have been reported.

(b) As trimethylsilyl ethers - The trimethylsilyl ethers of sorbitol, mannitol and xylitol can be chromatographed. The mannitol and sorbitol derivatives, however, are difficult to separate (Ref. 4). Sorbitol may be determined as its trimethylsilyl ether derivative on SE 30 (Ref. 3).

(v) Ion-exchange - Automated ion-exchange chromatography was found to be suitable for the determination of mannitol in aqueous ethanolic extracts of chocolates and toffees (Ref. 5).

(3) Colorimetric methods

The blue complex formed by xylitol in alkaline copper sulfate solution may be used to determine xylitol in canned foods (Refs. 6 \& 7). Oxidation of an aqueous extract with potassium dichromate-sulfuric acid allows estimation of total polyhydric alcohols by measurement of unreacted dichromate (Ref. 16).

(4) Titrimetric

Sorbitol in lemonade is determined by periodate titration after correction for interfering sugars (Ref. 17).

(5) Gravimetric

Sorbitol is determined in chocolate products as dibenzylidenesorbitol (Ref. 1). 
(6) Spectropolarimetric

The optical rotation of the molybdate complex of mannitol is measured at low acidity. At high acidity both mannitol and sorbitol complexes exhibit optical rotation. After correction for the effect of sugars by measuring the optical rotation of the sample in the absence of molybdate, the sorbitol concentration can be determined by difference (Ref. 18). A similar method using molybdate complexes involves measurement of optical rotation at $420 \mathrm{~nm}$, where only sorbitol exhibits rotation, and at $480 \mathrm{~nm}$ where both sorbitol and mannitol are optically active. Mannitol is calculated by difference after correction for glucose (Ref. 19).

\section{REFERENCES}

1. J. Vollaire-Salva and H. Chaveron, Ann. Falsif. Expert Chim. 56, 262 (1963); cited in Analyt. Abstr. 12, 334 (1965).

2. H. K. Hundley, J. Assoc. Offic. Analyt. Chem. 51, 1272 (1968).

3. E. Fernandez-Flores and V. H. Blomquist, J. Assoc. Offic. Analyt. Chem. 56, 1267 (1973).

4. H. G. Jones, D. M. Smith and M. Sahasrabudhe, J. Assoc. Offic. Analyt. Chem. 49,1183 (1966).

5. O. Samuelson and H. Stromberg, J. Food Sci. 33, 308 (1968).

6. Z. A. Markh, A. I. Starkina and D. M. Chalik, Otkrytia Isobret., Prom. Obraztsy, Tovarnye Znaki 46, 113 (1969); cited in Chem. Abstr. 72, 120255V (1970).

7. L. Fiseris, S. Beniusite, J. Maciuniene and J. Slezene, Konserv. Ovoshchesush. Prom. 23, 33 (1968); cited in Chem. Abstr. 70, 76502f (1969).

8. E. F. Marino and T. H. Zabal (1963); cited in Analyt. Abstr. 12, 1431 (1965).

9. A. Menger, Getreide Mehl Brot 26, 126 (1972); cited in Chem. Abstr. 77, 73757b (1972).

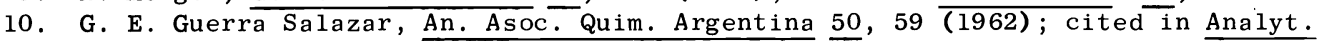
Abstr. 10, 2333 (1963).

11. F. Tateo, Sci. Aliment. 16, 189 (1970); cited in Chem. Abstr. 73, 119288x (1970).

12. Z. A. Coles, Jr., and R. P. Upton, J. Assoc. Offic. Analyt. Chem. 55, 1004 (1972).

13. G. P. Tikhomirova and V. I. Kalityvansika, Ukr. Khim. Zh. 38, 1166- (1972); cited in Analyt. Abstr. 25, 1921 (1973).

14. G. Mannius, F. P. Mahn, V. S. Venturella and B. Z. Senkowski, J. Pharm. Sci. 61, 1831 (1972).

15. J. A. Hause, J. A. Hubicki and G. G. Hazen, Analyt. Chem. 34, 1567 (1962).

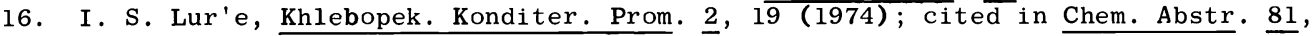
$24274 \mathrm{r}(1 \overline{974})$.

17. F. H. L. van Os and E. T. Elema, Pharm. Weekbl. Ned., 103, 205 (1968); cited in Analyt. Abstr. 16, 3252 (1969).

18. J. Dokladalova and R. P. Upton, J. Assoc. Offic. Analyt. Chem. 56, 1382 (1973).

19. E. I. Klabunovskii, L. N. Kaigorodova, O. A. Romanova and V. A. Pavlov, Zh. Anal. Khim. 29, 726 (1974); cited in Chem. Abstr. 81, 89904r (1974).

\section{ASPARTAME (INN)}

Chemical name: Methyl L-C.-aspartyl-L-2-phenylalaninate.

Physical properties: Aspartame is a white crystalline solid, m.pt. 248-250 $0^{\circ}$ Aqueous solutions of aspartame are most stable in the pH range 3-5 and at low temperature.

Analytical methods

(1) Clean-up methods

(i) Extraction - Aspartame is isolated from foodstuffs with methanol (Ref. 1).

(2) Chromatographic methods

(i) Thin-layer chromatography - Aspartame can be separated from possible decomposition products on silica gel using chlor of orm:methanol:water:acetic acid $(64: 30: 4: 2)$ as solvent.

(ii) Detection of spots - Visualization can be accomplished with ninhydrin (2,2-dihydroxyindane-1,3-dione) and sulfuric acid (Ref. 2) or with potassium iodide-starch solution after exposure of the plate to tert. butyl hypochlorite vapour (Ref. 1 ).

(iii) Gas chromatography - Aspartame can be determined after conversion to its diketopiperazine derivative by analysis of the latter as its silyl derivative on $3 \%$ ov-1 (Ref. 1). The silyl derivative of aspartame can also be analyzed on $15 \%$ ov-101 (Ref. 3 ).

(3) Spectrophotometric method

(i) Spectrofluorometric - Aspartame can be estimated by measurement of fluorescence of the reaction product of the sweetener, ninhydrin and phenylacetaldehyde (Ref. 1). This reaction, specific for primary amines, is readily amenable to automation. 


\section{REFERENCES}

1. G. D. Searle and Co. - private communication.

2. M. Brenner and A. Nielderwieser, Experientia 16, 378 (1960).

3. I. Purda, P. D. Malizia, M. G. Kolor and P. J. Vernieri, J. Agr. Food Chem. 23, 340 (1975).

\section{GLYCYRRHIZIN}

Chemical name: Glycyrrhizinic acid, glycyrrhizic acid.

Physical properties: Glycyrrhizin is freely soluble in hot water and alcohol, but practically insoluble in ether $[\alpha]^{17}+46.2^{\circ}(\mathrm{C}=1.5$ in alcohol $)$. Ammonium glycyrrhizinate is soluble in ammonia, water or glacial acetic acid. $[\alpha]_{D}^{20}+46.9^{\circ}$ The U.V. absorption: $\varepsilon=11400$ at $\lambda_{\max } 248 \mathrm{~nm}$ 。

Analytical methods

Quantitative determinations are based on glycyrrhetinic acid, the aglycone of glycyrrhizin. (1) Clean-up methods - After acid hydrolysis in acidic dioxane-water, the aglycone, glycyrrhetinic acid, may be extracted with chloroform (Refs. 1, 2 \& 3). This allows determination of glycyrrhizin in carbonated beverages (Ref. 2).

(2) Chromatographic methods

(i) Gas chromatography

(a) Methylation - The methyl glycyrrhetinate formed by methylation of the aglycone with diazomethane can be chromatographed on 5\% SE 30 (Ref. 3).

(b) Silylation - Silylation of the aglycone yields the silyl ester which is determined by gas chromatography on $1.5 \%$ OV-1 (Refs. 1 \& 2 ).

\section{REFERENCES}

1. D. Larry, M. J. Fuller and P. G. Harrill, J. Assoc. Offic. Analyt. Chem. 53, 698 (1970).

2. D. Larry, J. Assoc. Offic. Analyt. Chem. 55,570 (1972).

3. T. Vondonhof, K. W. Glombitza and M. Steiner, Scientia pharm. 41 , 155 (1973); cited in Analyt. Abstr. 26, 461 (1974).

\section{DIHYDROCHALCONES}

Chemical names: Naringin dihydrochalcone

Neohesperidin dihydrochalcone

Hesperidin dihydrochalcone

Analytical methods

A method for the chromatographic separation and detection of the dihydrochalcone sweeteners has been described. However, no methods are available for the quantitative determination of these compounds in foods.

(1) Chromatographic methods

(i) Paper chromatography - Separation can be obtained on Whatman No. 1 paper with $10 \%$ aqueous acetic acid as developing solvent (Ref. 1).

(ii) Thin-layer chromatography - Commercially prepared polyamide sheets, developed with nitromethane-methanol (3:2), separate some of the sweeteners (Ref. 1).

(iii) Detection of spots - Acidic sodium borohydride containing a small amount of 4,5-dichloro-3,6-dioxocyclohexa-1,4-diene-1,2-dicarbonitrile gives immediate colour with dihydrochalcones (Ref. 1). Flavanones and flavanoids respond weakly, if at all. Bisdiazotized benzidine may also be used to detect dihydrochalcones as well as other pkenolic compounds (Ref. 1).

(2) Paper electrophoresis - Electrophoresis using $0.1 \mathrm{M}$ sodium borate electrolyte may be used to separate the dihydrochalcone sweeteners (Ref. 1).

\section{REFERENCE}

1. B. Gentili and R. M. Horowitz, J. Chromatogr. 63, 467 (1971). 